\title{
A PASSAGEM DO INFANS AO PUER NO SISTEMA MUNDO GUARANI
}

\author{
The Passage From the Infans to Puer in the Guarani world System \\ El Paso de lo Infans a Puer en el Sistema Mundo Guaraní
}

WiLLIAM BEZERRA FigUeIREDO

\begin{abstract}
Resumo: A educação Guarani está imbricada no sistema palavra-alma-mundo (Teko) onde a criança se desenvolve em busca de um modo de ser belo e bom. Estas características que levam os Guarani a compreender a passagem do infans ao puer estão relacionadas com a maturidade da palavra-alma divina, que amadurece dentro da criança. Quando esta começa a falar é entendido que a mesma alcançou o momento da imposição do nome. Marcar esta passagem com o batismo tem grande sentido para a comunidade, onde cada palavra é única e sagrada. Falar é um momento de grande festividade, e muito importante, pois das ambas celestes as divindades se apresentam através de cada criança. O nome é a alma e é a palavra que cria horizontes de mundos diversos, e a conexão com a liberdade de ser é fundamental para que amadureça esta força que jaz no interior da criança, como semente no nhemongarai. Este período do pré-natal até dois ou mais anos da criança é repleto de cuidados, que pressupõe um sistema mundo complexo, na permissão ao lúdico, e a experimentação das crianças como forma de compreensão profunda do processo psicomotor e do desenvolvimento cognitivo do infans até o puer.
\end{abstract}

Palavras-chave: Educação Guarani; Teko; Palavra-Alma-Nome; Nhemongarai; Rito de Passagem.

\begin{abstract}
The Guarani education is related in the system word-soul-world (Teko) where the child is in a development path of becoming being good and beauty. Those Guarani traits makes them understand the passage of the infans to the puer as related to the maturity of the divine word-soul, that is being natured inside the child. When it starts to speak, it's understood that the child achieved the moment for name imposition. That passage is marked by the baptism, and that has a great meaning for the community, where every word is unique and sacred. To speak is a moment of great festivity, and it is very important because from the heavenly the deities show themselves through each child, as the seed of nhemongarai. The period from the pre-birth until the first two years of life is full of caring for the child's needs, which can be assumed as a complex system that allowed the child to live the ludic and also to have life-experiences as a manner to build a profound comprehension of its own psicomotricity and cognitive development.
\end{abstract}

Keywords: Guarani educacion; Teko; word-soul-name; Nhemongarai; rite of passage.

Resumen: La educación Guaraní está integrada en el sistema palabra-alma-mundo (Teko) cuando el niño se desarrolla en busca del modo de ser bello y bueno. Estas características conducen a los guaraníes a la comprensión del paso del infans a puer están relacionados con la madurez de la divina palabra-alma, que madura en el niño. Cuando el niño comienza a hablar se entiende que se ha alcanzado el momento de la imposición de su nombre. Marcar la iniciación con el bautismo tiene un gran sentido de la comunidad, donde cada palabra es única y sagrada. Hablar es un momento de gran fiesta, y muy importante, porque desde las ambas celestes las deidades se presentan en los niños. El nombre es el alma y es la palabra que crea horizontes de muchos mundos, y la conexión con la libertad de ser es fundamental para madurar esta fuerza que se encuentra dentro del niño, como semilla en el nhemongarai. Este período prenatal hasta los dos años o más que el niño está lleno de atención, lo que presupone un sistema complejo de mundo, el paso para la autonomía lúdica y la experimentación de los niños como una forma de conocimiento profundo del proceso de desarrollo psicomotor y cognitivo de los infans al puer.

Palabras-clave: Educación guaraní; Teko; Palabra Alma-nombre; Nhemongarai; Rito de paso.

\section{Introdução}

Neste artigo defendemos a tese das idades da vida apresentada pela fenomenologia (Josgrilberg, 2015), abrindo um campo de pesquisa para observar o fenômeno em diversas dimensões, entre elas a visão de mundo de diversas culturas sobre estas passagens, especificamente entre os índios Guarani. Observando o fenômeno da passagem das idades na cultura Guarani, percebemos o conjunto de práticas que culturalmente estabelecem as relações sociais da comunidade a partir desta vivência.
Objetivamos observar como os Guarani veem a passagem da criança não falante à falante. Um processo de aquisição de linguagem, que na cultura indígena pressupõe um conjunto complexo cerimonial e de conduta do grupo.

O "sistema mundo" da linguagem é fenomenologicamente inaugural para a aquisição espaço-temporal do sujeito em qualquer etnia ou grupo social, e neste sentido, os Guarani tem mostrado que este momento é fundamental para o destino da comunidade. Neste caso a relação entre o nome do sujeito e sua relação direta com o "espírito", que advém das esferas celestes. 
Partindo da tipologia latina sobre a divisão das idades, adotamos termos para que possamos observar intuições fenomenológicas sobre estes processos da vida, e simultaneamente comparando com a literatura antropológica, que nos muni dos relatos sobre a forma Guarani de constituir mundo. Esta transição da criança não falante até a falante se inicia no útero, e é efetivamente compreendida dentro do sistema mundo Guarani, dentre uma compreensão cosmológica, E não nos processos como aparece de cuidado da criança desde a barriga da mãe, até sua inserção no mundo da linguagem com o batismo do nome.

\section{Teko}

As Tekoas (literalmente lugar de costumes), aldeias, são o lugar onde se estrutura o conhecimento e formação dos Guarani Mbya. Todo o conjunto de saberes que a criança deve aprender está vinculado ao modo de ser Guarani o teko. Teko Porã, modo de ser bonito, adequado, vida correta, feliz etc. Dentro deste modo de ser Guarani encontramos o sistema educacional. A formação da criança infans ${ }^{1}$, aquela que ainda não fala, e, neste contexto, a criança que é em potência o que será para a comunidade Guarani. Seu nhê’é (nome-alma-palavra) compreende este destino.

Para os Guarani, 'ã tem esta significação, que na nossa língua portuguesa não podemos abarcar sem esta complexidade da alma-nome-palavra, pois estes elementos estão imbricados entre si. 'ã é a direção da nhê'é, 'ã pode ser estar de pé, levantado; também pode ser sombra, e nesse caso, faz sombra porque está diante da luz; 'ã é o ser que têm todas as características para ser em comunidade e efetuar seu destino como sujeito.

A criança no sistema mundo (conjunto de saberes, língua, crenças, práticas rituais etc.) dessas comunidades, tem uma nhê'é que descende do alto, das regiões celestes, amba. Cada uma destas regiões são domínios, e subníveis de divindades das quais emana a nhếé. O yvyra'i já ou Xaramoi (Sharamoi etc.), que é o xamã da comunidade, vê o 'ã da criança durante a cerimônia de batismo, o nhê'é é este sentido, direção da criança, seu teko. Na concepção Guarani, o que determina o nome é justamente a região de onde vem a alma da criança, não sendo jamais uma decisão arbitrária dos pais. É com base no "lugar de onde vem a alma" que o nome será constituído (Borges, 2002, p. 54).

Também entre os Mbya, o xamã é designado por mitã renoi a (aquele que dá nome as crianças). Nhê’é é um princípio terreno, ligado à carne e seu caráter perecível, e, simultaneamente um princípio divino, ligado à palavra-alma-nome.

\footnotetext{
Infans é a designação para a criança desde o feto até a fase em que adquire domínio sobre a fala.
}

\section{A nhê'é como linguagem}

Para os indígenas Mbya, o processo de batismo do nome se atém fundamentalmente às essas normas, e quando o menino ainda não possui nome, ele está sujeito à cólera, raiz de todo o mal, assim, somente quando se chame pelos nhê’é deixarão de encolerizar-se. Este nome é parte integrante da pessoa e é designado com a expressão 'ery mo’ ã a', aquele que mantém de pé o poder de dizer (Cadogan, 1992).

Esse processo pode demorar, mas sempre é relacionado ao desenvolvimento da criança, quando esta começa a andar e em muitos casos quando começa a falar:

A preparação para assegurar a vida e alma da criança começa já durante a gravidez. A mulher nesse tempo deve abster-se de toda comida pesada (banha, sal etc.) e lhe está tabuada a carne de um grande número de bichos do mato. (...) Assegurar o crescimento da alma da criança é a maior preocupação dos pais. Pais e filhos estão em "estado quente" e são numerosas as ameaças contra as quais se tem que defender. Continuam as proibições alimentares. $O$ pai deve se abster de trabalhos pesados. Deve, sobretudo, evitar comportamento violento. Arco e flecha ou arma de fogo não deve usar nem para caçar. Mas pode pescar e colocar armadilhas. A criança mama quando quer, recebe o máximo de atenção, procura-se satisfazer suas necessidades. O período de lactência estende-se até os dois anos, ou às vezes mais. $\mathrm{O}$ desenvolvimento da alma, que em guarani é chamada "palavra", se considera completo quando a criança começa a pronunciar suas primeiras palavras. É então quando o "vidente", uma classe de pajés, talvez vá descobrir o nome religioso da criança, isto é, o nome daquela alma-palavra estabelecido já antes do seu envio para se assentar, como sobre um banquinho, no corpo da sua futura mãe (Meliá citado por Borges, 2002 p. 58).

Hoje, com a proximidade dos Guarani com a sociedade ocidental, as crianças recebem nomes de Jurua (não-índio), para motivos de registro civil, pois podem demorar até dois anos, ou mais, para que o nhê'é se aproxime por definitivo da criança. Em geral, tal processo está ligado ao desenvolvimento psicomotor da criança, ela é, portanto, desde o feto, preparada para a nhê'é ser, observada e cuidada, de forma a se estabelecer a partir do 'ã. Neste sentido o conceito Guarani de educação é o mesmo do universo mítico de sentido, e remonta ao feto da criança. $\mathrm{O}$ feto já é o momento de observância da criança, portanto:

O principal objetivo dos adultos guarani é possibilitar a formação do que eles chamam de guarani ete, ou seja, um guarani de verdade. Um adulto que possua todas as características de um bom homem guarani, que, entre outras, é ser religioso e avesso à sedução 
das coisas do mundo não-índio. Nos primeiros anos, a grande preocupação dos pais é assegurar o crescimento da alma, pois a criança ainda está fraca e vulnerável. Nesse período é comum os pais adotarem a criação de animais domésticos como galinhas e cachorros, que servem de anteparo protetor a qualquer malefício que venha do mundo exterior, como doenças e feitiços, pois os pais e os filhos ainda estão vulneráveis às maldades do mundo (Borges, 2002, p. 57).

O cuidado desde o feto é hoje estudado pela ciência cognitiva, psicologia etc. e vêm mostrando bons resultados, os Guarani já atuam neste sentido desde tempos imemoriais. A educação Guarani tem seus primórdios na observância deste caráter da nhê'é, que é o conjunto do psiquismo da comunidade, é um verbo, um som, um corpo da cultura. A fala é a entrada no mundo, e por isso o sacerdote tem a legitimidade de nomear a criança quando este começa a ganhar forma no ‘ã, que significa que o bebê está se alinhando com os caminhos da tradição simbólica mítica. "A experiência religiosa guarani é constituída pelas formas da relação com o divino, pelas formas do canto e da dança, pelas formas da palavra profética, mais do que pelo conteúdo de suas crenças” (Meliá, 1989 p. 330).

A fenomenologia também tem se ocupado deste momento crucial de formação do sujeito infans, entendendo que hoje, com o avanço da ciência podemos observar já no feto a relação da criança com o mundo externo da cultura. Neste caminho de composição da identidade narrativa o infans passa para falante e é recebido no grupo como sujeito com nhê'é, ou seja, capaz de receber a cultura do seu povo, é quando ele passa para outra etapa da vida a de puer:

A percepção do infans (do corpo nãofalante) deve ser estendida ao feto. O feto observado na ultrassonografia ou mesmo na vivencia natural da mãe realiza uma série de movimentos que parecem fundamentais para o desenvolvimento. A fenomenologia visa aqui a correlação de corpos e de mundos. O corpo nãofalante do feto é dado como predisposto para a fala e para a interação simbólica com a cultura falante. Essa interação fenomenologicamente dada pode ser ilustrada pela pesquisa empírica que aponta para a transmissão da língua ao infans passa pelo corpo materno falante que repercute no útero. A familiaridade com a voz materna é um indício para a fala futura. O corpo nãofalante se desenvolve em boa parte como "disposição para a linguagem”. A linguagem não é apenas um desenvolvimento do corpo ou do espírito: a linguagem só opera com ambos. O espírito humano fala como corporeidade e se desenvolve como corporeidade no entrelaço do "corpoespírito". O feto não tem apenas uma formação fisiológica, já que a partir de um determinado momento a interação com a paideuma (cultura falante educadora) se intensifica. A gênese de nos- sas relações sociais e culturais começa nas formações do corpo infans fetal em sua constituição por movimentos, predisposição para a linguagem e reações ao mundo útero-maternal. O feto da dependência total prepara-se para uma busca de progressiva autonomia no ambiente cultural e que se estenderá pela vida (Josgrilberg, 2015, p. 13).

Existe, entre os Guarani, uma relação direta entre identidade e nhê'é maduro já instituído pelo ‘ã, pois este pode agora se relacionar com o grupo social, "Até os 3 anos, as crianças guarani são internalizadas culturalmente no reko (“costume") por todo o grupo social. É papel da sociedade como um todo a formação daquele indivíduo em um bom guarani, partilhando o seu dia-a-dia desde a interação do nascimento até a imersão completa na rotina cultural" (Borges, 2002, p. 58). A abordagem da educação não está distante da vida, e educar e viver são experiências compartilhadas, não há divisão ou meios para afirmar que a educação está fora da vida.

A notável relação entre a linguagem e a educação, visto que, ser Guarani e ter uma palavra-nome-alma é um complexo dispositivo que dialoga com o universo da língua, mas, com o pensamento e a cultura da comunidade. A criança está pronta para desfrutar da cultura e, por isso, se diz que está pronta para a vida de falante, $p u e r^{2}$, e madura para receber os costumes.

A nhê'é, é a própria pessoa, é o processo de viver e falar, narrar-se e narrar a vida, e ser narrado. A identidade complexa, que compõe a relação dos sujeitos com sua região celeste, assim como sua missão profética, está entrelaçada no educar e no viver. É a forma como o sujeito constitui mundo, a palavra é a vida, a ponto de identificar vida e morte da nhê'é nos processos de cura:

Os Guarani prestam tanta importância ao nome que lhes foi revelado a ponto de, como último recurso em caso de doença de morte, o rezador rebatizar o doente por meio de rituais, a fim de que o mal não continue naquele corpo. Não é raro encontrarmos guarani que, ao saudá-lo pelo nome, ele finja não ouvir e faça questão de não atender. De imediato, outros nos avisam que o seu nome foi mudado, ele agora possui um novo e se voltará apenas a este. No antigo nome todas as doenças e os eventuais feitiços ficam aprisionados; é urgente esquecê-lo o mais breve possível, a fim de que estes malefícios também desapareçam. O nome guarani é um pedaço de seu portador, ou mesmo, quase idêntico a ele, inseparável da pessoa. O guarani não 'se chama' fulano de tal, mas ele ‘é’ este nome (Borges, 2002, p. 56)

Entendendo o mito como linguagem e como sentido, a voz e o gesto são concomitantes, a oralidade do mito é um meio de conhecimento e formação educacional. A

\footnotetext{
Puer é a designação para a criança que adquire domínio sobre a fala até o período da adolescência (adolescens), é a criança propriamente dita.
} 
oralidade é educativa e todo educador deveria considerar isso como princípio, que há uma alma na palavra, que os nomes carregam algo essencial e espiritual, pois nas culturas tradicionais o conhecimento é dado através da palavra performativa, que é a alma, o ouvir, o dizer, e a comunicação, ou ligação, com as esferas divinas.

A linguagem humana compreende todo o universo particular da alma, a palavra, o nome é repleto de vida, de predestinação de energia sobrenatural 'ã. E por isso a criança só pode ser nomeada quando esta força está em ato nela própria, sua capacidade de comunicar-se com o mundo:

Ne'ë e ayvu, os dois termos que, dependendo do grupo, são usados para falar da alma, da voz, da vida, da palavra, são apresentados por Cadogan como 'linguagem humana'. Esta linguagem, no entanto, é apreendida através da audição da voz dos pássaros, da corredeira, das árvores e das pedras. Tudo que está vivo tem ñe'ë, que os humanos podem ouvir se estiverem atentos. José Morales, um dos meus informantes, afirma que tudo o que aprendeu o fez sozinho, andando no mato e ouvindo (Montardo, 2002 p. 151 e 152).

É o espaço para o laissez-faire da criança, que experimenta a natureza das coisas, estimula o processo psicomotor, pela liberdade de uso dos objetos e dos elementos do entorno, das águas, do mato, do barro, das brincadeiras, através do conjunto da experiência motora e de identificação do enfrentamento com a realidade, e dessa forma, ele avança no campo da linguagem e também na alma:

Na cultura Guarani destaca-se o papel da mediação dos adultos na aprendizagem da criança e a importância do brincar, o nhemboarai. Ao relatar as brincadeiras tradicionais, o professor Teodoro Tupã informa que estas eram planejadas, organizadas e coordenadas por adultos. Os brinquedos são feitos pelos mais velhos, enquanto a criança observa atentamente o processo. Mencionou a peteca de palha de milho, uma brincadeira de meninas; o arco e flecha, uma brincadeira de meninos com mais de 8 anos; o esconde-esconde, brincadeira tradicional com variações em que o adulto responsável esconde um pedacinho de vara ou faz um sinal em determinado lugar, árvore ou chão, e as crianças têm que encontrá-lo. Nesse jogo há diversas regras a serem seguidas, como a divisão por idade e sexo. Para o professor Teodoro Tupã, [...] todo jogo é relacionado à cultura. Através do jogo a criança aprende a regra da nossa cultura (Faustino, 2012, p. 258).

O aprender é uma síntese do cantar, do brincar, do dançar, da harmonia celeste, pois "os Guarani têm a responsabilidade de cantar e dançar: se não o fizerem, estarão colocando em risco a continuidade da vida no planeta, pois, assim como os deuses mobilizam uns aos outros tocando seus instrumentos, os homens também o fazem" (Montardo, 2004, p. 85). Ou seja, a linguagem é o campo para o qual a criança é projetada da infans até a puer, num universo de ludicidade e musicalidade (Montardo, 2002) onde começa o processo de comunicação estrito, de aprendizagem sobre a paideuma, o Teko. E este processo é comemorado como todo rito de passagem por cerimônias, e a cerimônia do batismo é esse momento.

\section{O batismo e a palavra como inserção do puer no sistema mundo}

Esse processo do batismo das crianças, o nhemongarai (fazer-se sagrado, batismo da semente), é um período amplamente significativo, e todas as comunidades esperam por este feito, em que xamãs vêm para observar se o 'ã já está na criança e se a mesma pode receber o nhê’é. $\mathrm{O}$ nhemongarai se confunde com a cerimônia do chá, que é o batismo da erva mate ka'a. Ambos ocorrem na ara yma e ara pyau, nas palavras de Marcos Tupã (2015):

Somos um povo bastante religioso. No nosso dia a dia, o guarani está sempre em busca ou ligado a essa força espiritual de Nhanderu, do Sol. Todas as coisas que fazemos - nosso trabalho, as brincadeiras das crianças - são voltadas para essa busca. Nosso calendário não é como o do jurua, ele é dividido em Ara Pyau, tempo novo, e Ara Ymã, tempo velho. Essa divisão está ligada à trajetória que o Sol faz. O Ara Pyau para nós é o período de primavera e verão, quando o dia é mais longo e o sol faz uma caminhada maior, e o Ara Ymã é no outono e inverno, no período de frio, nesta época em que o dia é mais curto (Tupã, citado por Figueiredo, 2015, p. 13-14).

Como a cerimônia é realizada duas vezes ao ano, as crianças podem esperar mais tempo para receber a nhê'é. O batismo acompanha a cosmovisão Guarani, e ajuda a ratificar a presença do sagrado no cotidiano, pois, desde as brincadeiras, como comenta Tupã (2015), já estão voltadas para a busca de educar para o Guarani Ete. O batismo da erva ka'a é muito importante, ao lado de fumo, petỹ, pois são elementos primordiais da cerimônia cotidiana na casa de rezo (o'opy):

Para a realização desse ritual os indígenas colhem galhos da árvore de erva-mate para depois amarrarem em galhinhos. Estes são presos e suspensos no amba (região central e dianteira), na casa de rezas. Durante toda a noite, eles são consagrados e benzidos pelos rezadores da comunidade. No dia seguinte, as folhas são socadas no pilão e a farinha da erva-mate é colocada nas cuias e depois encaminhada a seus donos, após serem benzidas durante a segunda noite. (...) Nesta cerimônia é dominante um sentido de descoberta e de 
revelação dos acontecimentos futuros. Há um clima de fé e de esperança (mbojerovia) durante os cantos e danças que se propagam por toda a noite e onde está onipresente a força do cachimbo (petỹgua) e do fumo (petỹ). (...) É também convincente o fato de nas aldeias onde se realiza esta cerimônia predominar um clima de dedicação à tradição, contra a invasão incontrolável do teko axy. Sobretudo, torna-se real a ideia de evitar ou adiar a aniquilação do mundo (Carvalho \& Godoy, 2011, p. 133).

A presença do tabaco e do uso da erva têm o propósito de expandir a consciência do grupo, e prevê que todos fiquem com o corpo leve (rete vevui), pronto para voar. É uma experiência típica do xamanismo, a experiência do voo, como é apontada por Mircea Eliade (2002). A educação formal contrasta com este ambiente simbólico educativo, que é mais próximo da paideuma, pois é no contato com a palavra-alma-nome que o sujeito repleto de ‘ $\tilde{a}$ entra pra vida-palavra do Teko Guarani e passa buscar pelo Guarani Eté:

Seria um grande equívoco confundir o papel social do xamã com o da escola. Entende-se, como Gow (1991), que a escola, para as comunidades indígenas, tem a função de traduzir o mundo social do não índio; por conseguinte, ela ganha em importância, pois além de ser um espaço de conhecimento do outro, é também o espaço onde ficam as crianças. Por outro lado, o xamã é o tradutor do mundo não humano, das forças da natureza. É neste sentido que a relação com a natureza é fundamental para a educação tradicional guarani e torna-se uma questão da própria condição humana deste povo (Carvalho \& Godoy, 2011, p. 142).

É equivocada, portanto, a tentativa de educação ocidental para os Guarani, pois podemos averiguar que a formação do sujeito tem outros parâmetros de constituição pelo modo de ser desta comunidade. O espaço da o'opy é um espaço "outro", que a escola ocidental não conseguiu alcançar. Pois esse espaço do sagrado, onde ocorre a educação, está entre este mundo e o outro, como microcosmo e relação de reflexo mau feito do mundo das divindades, a casa de rezo o'opy representa a geometria celeste, pois em cada uma das suas direções se associa uma amba.

O lugar de aprender é o lugar onde não existe divisão dos mundos. O próprio Guarani não pode ser um sujeito dividido, pois seu nhê'é já representa que ele é bipartidário simultaneamente dos mundos no mundo. A educação é antes uma performance, ou seja, uma ação performativa:

Cada um desses homens, ao seu tempo, levanta e começa a caminhar em direção a uma das paredes dessa casa templo, e como templo, essas paredes encerram, mas estabelecem um lugar para o cultivo e pratica de algum conhecimento, e no caso desse povo, um conhecimento ligado ao ancestral, nessa parede de blocos de barro e madeira ficam alguns elementos de sua cultura, como colares, tambores, bambus, e estão nesse lugar compondo um altar, esses elementos elevados são esfumaçados, defumados pelo sopro do homem após o trago ao cachimbo que incandesce o fumo, após passar por colares, bambus e canecas que escorrem de significado e como se eles fossem a mente desse mundo, caminhando lentamente, aquele que o fuma entra em forma circular no espaço, um caminhar lento, como se as solas do pés entrassem em contato com um chão macio e profundo, a cada passo dado no espaço caminha para uma alteração na passagem do tempo, como se dentro desse circular espacial, o tempo descendesse em ascendência ancestral, desacelerando o tempo cotidiano das coisas, expandindo o estado das percepções das coisas (Muniz, citado por Figueiredo, 2015, p. 47).

Outro tempo é instaurado, diferente do tempo cotidiano. Tudo ocorre in illo tempore, num tempo mítico da criação (Eliade, 2001). O rete vevuí é um tempo de andar lento, de voar, de se conectar com as regiões celestes, pois a ritualidade tem essa dimensão de expansão do tempo. Em uma entrevista intitulada "A história de um guarani é a história de suas palavras", publicada na revista do Instituto Humanitas Unisinos, Bartolomeu Meliá (2010) fala sobre a educação Guarani:

Efetivamente. Para o guarani, a Palavra é tudo, tudo para ele é palavra. E a palavra nunca é a de um só. Portanto, é uma educação comunitária e ao serviço da comunidade, embora haja também uma palavra própria, poética, que chega pela inspiração, mas é colocada ao serviço de todos, especialmente nas celebrações rituais. Pelo que observei, o menino e a menina são socializados desde muito pequenos não só pelos pais e pelas mães, mas eles são postos em condições para que possam estar abertos às palavras que receberão por meio dos relatos que escutam no pátio da aldeia ou em sua casa, mas sobretudo por meio dos cantos rituais. Toda essa atividade é feita em um ambiente de tranquilidade e paz, sem gritos, nem golpes. Chama a atenção como os pais de crianças de dois, três ou quatros anos as fazem raciocinar com paciência quando fizeram algo incorreto. $\mathrm{O}$ ambiente é de grande liberdade. A história de um guarani é a história de suas palavras, palavras escutadas e palavras ditas, palavras inspiradas e palavras rezadas, palavras pronunciadas em uma assembleia e palavras apenas sussurradas na vida íntima. A educação escolar formal obedece a outro sistema que costuma trazer resultados desastrosos, sobretudo quando o docente vem do mundo dos brancos. No Brasil, no entanto, são agora numerosos os professores indígenas, alguns com formação universitária. São conscientes das grandes possibilidades que 
a escritura e o uso dos meios de comunicação digital oferecem, e se tornaram especialistas em seu manejo - muito mais do que eu, com certeza -, mas também estão muitos preocupados com os efeitos contrários que esses meios podem trazer ao sistema guarani (Meliá, 2010, seção 331).

A palavra-alma-nome é a base educacional da criança, imersa num sistema mundo onde ser é falar e tudo é sagrado. Nosso entendimento sobre o infans é muito vasto, e as novas tecnologias, juntamente com um olhar fenomenológico que busca o sentido, nos ajudam na compreensão do fenômeno da gestação e formação da criança. O modelo que encontramos na cultura Guarani é muito rico, em termos de cuidado e compreensão deste fenômeno da formação do sujeito, e merece estudos continuados.

\section{Considerações finais}

Importante percebermos que a educação Guarani está imbricada no sistema palavra-alma-mundo onde a criança se desenvolve em busca de um modo de ser belo e bom. Essas características, que levam os Guarani a compreender a passagem do infans ao puer, estão relacionadas com a maturidade da palavra-alma divina, que amadurece dentro da criança. Quando ela começa a falar, é entendido que a mesma alcançou o momento da imposição do nome, que já está na criança e apenas esperava pela maturação no modo de ser dela. A linguagem está presente desde o feto, e ganha sentido com o compartilhar coletivo dentro do grupo.

Marcar esta passagem com o batismo tem grande sentido para a comunidade, onde cada palavra é única e sagrada, não há “palavras ao vento”, a palavra e a vida são unas, e a condição paideuma é estabelecida por esta relação. O entrecruzamento do processo de comunicação divina e a educação tornam-se igualmente relevantes pois a divindade se faz viva em cada Guarani, se encarna em cada criança, e se faz verbo.

Falar é um momento de grande festividade, e muito importante, pois das ambas celestes as divindades se apresentam através de cada criança. O nome é a alma e é a palavra que cria horizontes de mundos diversos, e a conexão com a liberdade de ser é fundamental para que amadureça esta força que jaz no interior da criança, como semente que brota no nhemongarai.

O entendimento e o cuidado desde o feto mostram o entendimento e a sofisticação desta cultura milenar, que compreende o gênero humano como um advento sagrado, a palavra. A experiência das idades da vida é uma síntese integradora da busca maior do Guarani Eté, e com foco no cuidado, na permissão ao lúdico, e a experimentação das crianças é uma forma de compreensão profunda do processo psicomotor e do desenvolvimento cognitivo do infans ao puer.
Este período do pré-natal até dois ou mais anos da criança é repleto de cuidados, que pressupõe um sistema mundo complexo, e, esta sofisticação mostra a importância fundamental da vida, e muito devemos aprender e aplicar sobre este sentido do educar desde o feto, e educar sempre, e com o comprometimento de toda a comunidade.

\section{Referências bibliográficas}

Borges, P. H. P . (2002). Sonhos e nomes: as crianças Guarani. Cad. CEDES. 22(56), p. 53-62.

Carvalho, M. A. G. \& Godoy, M. G. G. (2011). Representações míticas guarani mbya: a palavra como fundamento da educação. Educação \& Linguagem, 14(23/24), p. 120-145.

Cadogan, L. (1992). Ayvu Rapyta: Textos míticos de los mbyaguarani del Guaíra. Assunção: Biblioteca Paraguaya de Antropología.

Eliade, M. (2001). O Sagrado e o Profano. São Paulo: Martins Fontes.

Faustino, R. C. (2012). Educação e religião Guarani no Paraná: estudo a partir do ritual Nimongarai. Práxis Educativa (Ponta Grossa), 7 (Nr Especial), p. 239-263.

Figueiredo, W. (2015). Projeto Sarau da Central - 5 anos: Intercâmbios, Oralidades e Culturas Tradicionais - Direitos Culturais e Gestão de Políticas Públicas. São Paulo: Editora Giostri.

Josgrilberg, R. (2015). Fenomenologia e Educação. Notandum 38 mai-ago. CEMOrOC-Feusp / IJI-Univ. do Porto.

Meliá, B. (1989). A experiência religiosa Guarani, O Rosto Índio de Deus. Petrópolis: Vozes.

Meliá, B. (2010). A história de um guarani é a história de suas palavras. Revista IHU Online, n. 331, s/p.

Montardo, D. L. (2002). Através do mbaraka - música e xamanismo guarani. Tese (Doutorado) - Programa de Pós-Graduação em Antropologia Social, Universidade de São Paulo, São Paulo.

Montardo, D. L. (2004). Uma antropologia da música Guarani. Tellus, 4(7), p. 73-91.

William Bezerra Figueiredo - Doutorando em Ciências da Religião e Graduado em Filosofia (UMESP-SP). Estuda Psicopatologia Fenomenológica na faculdade de ciências médicas da Santa Casa de São Paulo. É Especialista em gestão e politicas culturais e terapeuta integrativo e existencial; Professor convidado na Especialização em Filosofia da Religião da Faculdade de Humanidades e do Observatório de Violência Religiosa na Universidade Metodista de São Paulo. Há seis anos é coordenador do Instituto Inatekié \& Centro de Estudos Xamânicos na região do ABC Paulista e co-idealizador do Retiro Tape Porã - Centro de Estudos e Vivências Eco Xamânicas em Parelheiros-SP. E-mail: arteveiculo@hotmail.com

Recebido em 14.02.17

Primeira Decisão Editorial em 27.03.17

Aceito em 12.04.17 